\title{
Ring-shaped crack propagation in a cylinder under nonsteady cooling
}

\author{
V. A. Zhornik, Yu. A. Prokopenko, A. A. Rybinskaya \\ \& P. A. Savochka \\ Department of Theoretical Physics, Taganrog Pedagogical Institute, \\ Russia
}

\begin{abstract}
A quasistatic problem of thermoelasticity for a solid infinite cylinder with a ringshaped crack is considered. The cylinder is enclosed in a rigid thin heat absorbing shell with a slip joint which reduces thermal impact. The external surface of the shell is subjected to a linear heat transfer by radiation to the surroundings. We assumed that the cylinder had initially a temperature changing along the radius and the surrounding temperature was a function of time. The main result is an expression obtained for the stress intensity factor depending on time. Various particular cases are considered obtained both by the authors of this paper and by other scientists. An analysis of the dependences of the stress intensity factor (SIF) on time shows that with an assigned critical SIF, there are minimum and maximum crack sizes below and above which the crack will not grow under the given cooling conditions. For these dimensions, the maximum of SIF does not reach the critical value. For intermediate crack sizes, growth of the crack begins at the moment SIF reaches the critical value. Here, the crack first grows irregularly to the size for which at the given moment of time SIF is equal to the critical value. Extension of so called "hot "cracks in a solid cylinder is also considered. These cracks arise when a cold cylinder is placed in a fusion of the same material at the melted temperature. Further on this cylinder is rapidly taken out of the fusion and on its surface the melting layer linked with the cylinder surface arise. Under cooling of the cylinder, residual tensile stresses arise in the layer which may cause growth of ring-shaped surface cracks which are dangerous for further exploitation of this system.
\end{abstract}

Keywords: thermoelasticity, crack propagation, SIF, powdery covering. 


\section{Introduction}

A solid infinite cylinder of radius $r_{c}$ with an unloaded co-axial ring-shaped crack $\left(\mathrm{r}_{\mathrm{d}}<\mathrm{r}<\mathrm{r}_{\mathrm{c}}\right.$ ) coming to the surface of the cylinder was chosen for crack propagation analyses in deformed solids under nonstationary thermal loading. We assume that the cylinder is surrounded by the shell with a slip joint, i.e. the surfaces of the cylinder and the shell can slide freely relatively to each other to the axial direction.

It is assumed that the covered cylinder, with a constant initial temperature, is cooled over is entire surface through heat exchange with its constanttemperature environment. In this case, the heat flows are radial and the crack has no effect on heat propagation within the cylinder.

\section{Mathematical modeling}

In light of this, the solution of the thermoelastic problem is represented as the sum of two solutions,

$$
\begin{aligned}
& \sigma_{i j}=\sigma_{i j}^{T}+\sigma_{i j}^{P}, \\
& u_{i}=u_{i}^{T}+u_{i}^{P} .
\end{aligned}
$$

The first solution, obtained with the assumption that no cracks are present, satisfies the equations of thermoelectricity for an infinite cylinder in a generalized plain-strain state. This solution satisfies all boundary conditions except for those for the edges of the crack, which are loaded by a normal load

$$
\begin{aligned}
& \sigma_{z z}^{*}=\frac{\sigma_{z z}^{T}(1-v)}{\alpha_{T} E\left(T_{0}-\theta\right)} \\
= & 2 B i \sum_{n=1}^{\infty} \frac{\exp \left(-y_{n}^{2} F_{O}\right)}{y_{n} J_{0}\left(y_{n}\right)\left[\left(B i-\omega k y_{n}^{2}\right)^{2}+y_{n}^{2}(1+2 \omega k)\right]}\left\{2 J_{1}\left(y_{n}\right)-y_{n} J_{0}\left(y_{n} \frac{r}{r_{c}}\right)\right\}
\end{aligned}
$$

$\mathrm{y}_{\mathrm{n}}-\mathrm{a}$ root of equation

$$
\mathrm{yJ}_{1}(\mathrm{y})=\left(\mathrm{Bi}-\omega \mathrm{ky}^{2}\right) \mathrm{J}_{0}(\mathrm{y})
$$

Here $\mathrm{E}$ is the elastic modulus of the cylinder material; $v$ is the Poisson ratio; $\alpha_{\mathrm{T}}$ is the coefficient of lineral expansion; $\mathrm{Bi}=\frac{\alpha \mathrm{r}_{\mathrm{c}}}{\lambda}$ is the Biot criterion;

$$
\alpha=\alpha_{0} \frac{1}{1+\alpha_{0} \mathrm{~d} / \lambda_{\Pi}} ; \omega=\frac{\rho_{\Pi} \mathrm{c}_{\Pi}}{\rho c} \frac{1+\alpha_{0} \mathrm{~d} / 2 \lambda_{\mathrm{T}}}{1+\alpha_{0} \mathrm{~d} / \lambda_{\mathrm{T}}} ;
$$

$\mathrm{k}=\mathrm{d} / \mathrm{r}_{\mathrm{c}} ; \mathrm{d}$ - coating width. 


\section{Calculations}

For numeral analyses a solid cylinder of the radius $r_{c}=5 \cdot 10^{-3} \mathrm{~m}$ made of steel 45 (it's chemical composition: $\mathrm{Fe}, 0,42-0,49 \% \mathrm{C}, 0,17-0,37 \% \mathrm{Si}, 0,5-0,8 \% \mathrm{Mn} ; \rho=$ $7800 \mathrm{~kg} / \mathrm{m}^{3}, \mathrm{c}=470 \mathrm{~J} / \mathrm{kg} \cdot \mathrm{K}, \lambda=50 \mathrm{~W} / \mathrm{m} \cdot \mathrm{K}$ ) is chosen, coating is made of bronze Бp ОФ-10-1, (it's chemical composition: $\mathrm{Cu}, 9-11 \% \mathrm{Sn}, 0,8-1,2 \% \mathrm{P} ; \rho_{0}=8700$ $\mathrm{kg} / \mathrm{m}^{3}, \mathrm{c}_{0}=380 \mathrm{~J} / \mathrm{kg} \cdot \mathrm{K}, \lambda_{0}=100 \mathrm{~W} / \mathrm{m} \cdot \mathrm{K}$ ); it's width is $\mathrm{d}=0,25 \cdot 10^{-3} \mathrm{~m}$. The coefficient of heat transfer $\alpha_{0}=1,5 \cdot 10^{5} \mathrm{~W} / \mathrm{m}^{2} \cdot \mathrm{K}$. The porosity $\theta=0,54$. Using the formula for the porous medium

$$
\lambda_{\Pi}=\lambda_{0}(1-1,5 \theta) \text { for } \theta<0,6
$$

and the formula

$$
\begin{aligned}
& c_{\Pi}=c_{0}(1-\theta) \\
& \rho_{\Pi}=\rho_{0}(1-\theta)
\end{aligned}
$$

we obtain: $\rho_{\Pi}=4000 \mathrm{~kg} / \mathrm{m}^{3}, \mathrm{c}_{\Pi}=175 \mathrm{~J} / \mathrm{kg} \cdot \mathrm{K}, \lambda_{\Pi}=19 \mathrm{~W} / \mathrm{m} \cdot \mathrm{K}$.

As a result $\mathrm{k}=\mathrm{d} / \mathrm{r}_{\mathrm{c}}=0,05<<1, \omega \mathrm{k}=0,0065, \mathrm{Bi}=5$. In the case of covering absence $(\mathrm{d}=0)$ we obtain $\omega \mathrm{k}=0, \mathrm{Bi}=\alpha_{0} \mathrm{r}_{\mathrm{c}} / \lambda=15$.

Figures 1 and 2 show the relations between time $\mathrm{Fo}=\mathrm{at} / r_{c}^{2} \quad(\mathrm{a}-$ heat diffusing) and axial strains $\sigma_{z z}^{*}$ depending on the radius $r / r_{c}$ for the cases of the cylinder with the covering (Figure 1) and without it (Figure 2). As we can see from the graph on the figures powdery coverings essentially reduce thermoelastic stress in cylinder.

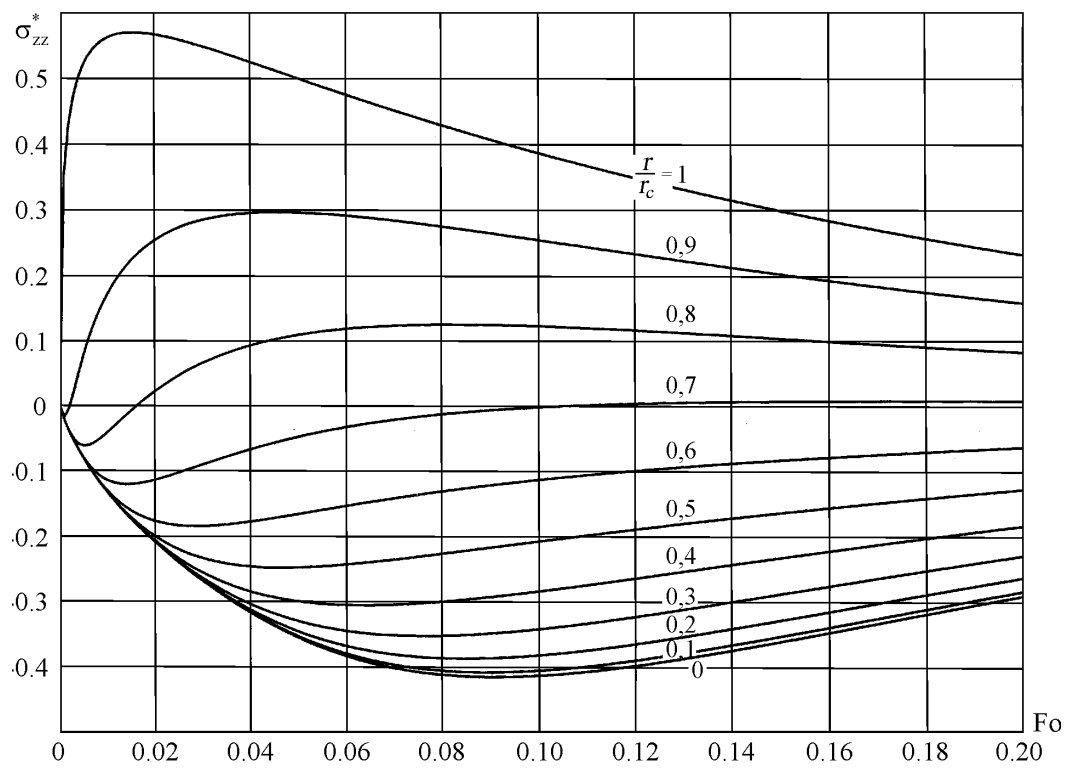

Figure 1: Diagram for $\sigma_{z z}^{*}$ depending on Fo for different $r / r_{c}$ (without covering). 


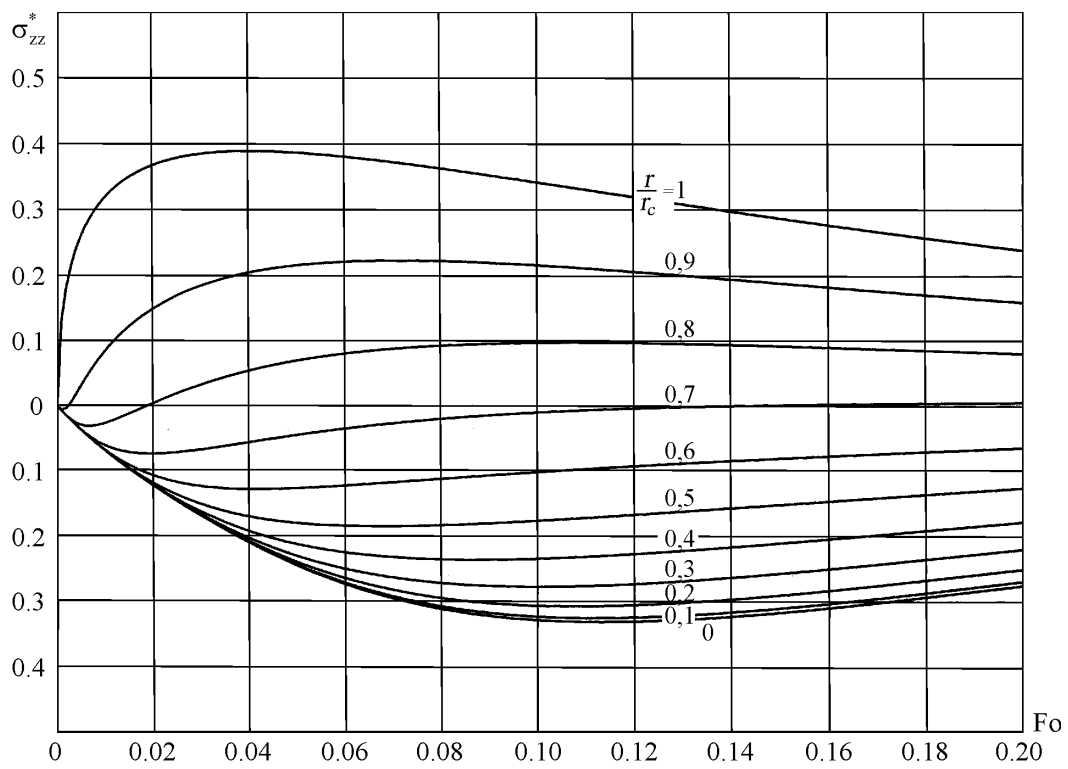

Figure 2: Diagram for $\sigma_{\mathrm{zz}}^{*}$ depending on Fo for different $\mathrm{r} / \mathrm{rc}$ (with covering).

In the case of plane-strain stress axial displacement is zero in the plane of the crack.

When added to the first solution, the second solution - from the isothermal theory of elasticity - satisfies all boundary conditions including those for the crack edges.

Because of symmetry conserning the plane of the crack, the second solution is for semi - infinite cylinder $(z>0)$ with mixed boundary conditions on the end wall. Through boundary condition for tangent stress is given on the end - wall. The condition of slipping joint leads to zero radial displacement and zero tangent stress component.

Mathematical setting of the problem is:

$$
\begin{array}{lll}
\sigma_{\mathrm{zz}}^{\mathrm{p}}=-\sigma_{\mathrm{zz}}^{\mathrm{T}}, & \mathrm{rd}<\mathrm{r}<\mathrm{rc}, & \mathrm{z}=0, \\
\mathrm{u}_{\mathrm{z}}^{\mathrm{p}}=0, & 0<\mathrm{r}<\mathrm{r}_{\mathrm{d}}, & \mathrm{z}=0, \\
\sigma_{\mathrm{rz}}^{\mathrm{p}}=0 & 0<\mathrm{r}<\mathrm{rc}, & \mathrm{z}=0, \\
\sigma_{\mathrm{rz}}^{\mathrm{p}}=0, & \mathrm{r}=\mathrm{rc}, & 0<\mathrm{z}<\infty, \\
\mathrm{u}_{\mathrm{r}}^{\mathrm{p}}=0 & \mathrm{r}=\mathrm{rc}, & 0<\mathrm{z}<\infty
\end{array}
$$

According to the problem (6) - (10) the calculation of stress-strain state of the cylinder with a ring-shaped crack is fulfilled. This solution allowed to us calculate stress intensity factor (SIF) as a criterion of crack propagation $[1,2]$. 
As is known, the solution of the problem from the isothermal theory of elasticity $\left(\sigma_{\mathrm{ij}}^{\mathrm{P}}, \mathrm{u}_{\mathrm{i}}^{\mathrm{P}}\right)$ reduces to finding the function $\chi(\rho, \zeta)$, having the form

$$
\chi(\rho, \zeta)=\sum_{n=1}^{\infty} \frac{r_{c}^{2}}{\lambda_{n}} B_{n}\left(\lambda_{n}\right) J_{0}\left(\lambda_{n} \rho\right) e^{-\lambda_{n} \zeta}
$$

Here, $\lambda_{n}$ are the positive roots of the equation of $J_{1}(\lambda)=0, \zeta=r / r_{c}$. The boundary conditions for the rigid shell (8),(9),(10) are satisfied identically through selection of the function $\chi(\rho, \zeta)$. By substitution

$$
\mathrm{B}_{\mathrm{n}}\left(\lambda_{\mathrm{n}}\right)=\mathrm{b}_{\mathrm{n}}\left(\lambda_{\mathrm{n}}\right)+\frac{2}{\mathrm{r}_{\mathrm{c}} \mathrm{J}_{0}^{2}\left(\lambda_{\mathrm{n}}\right)} \int_{0}^{\mathrm{r}_{\mathrm{d}}} \mathrm{g}(\mathrm{t}) \cos \left(\lambda_{\mathrm{n}} \frac{\mathrm{t}}{\mathrm{r}_{\mathrm{c}}}\right) \mathrm{dt}
$$

the unknown $B_{n}$ is determined from a pair of the ordinary equations constructed from the mixed boundary conditions assigned in the plane of the crack

$$
\begin{array}{lll}
\sigma_{\mathrm{zz}}^{\mathrm{p}}=-2 \mu \mathrm{F}(\mathrm{r}), & 0<\mathrm{r}<\mathrm{rd}, & \mathrm{z}=0, \\
\mathrm{u}_{\mathrm{z}}^{\mathrm{p}}=-\delta, & \mathrm{rd}<\mathrm{r}<\mathrm{rc}, & \mathrm{z}=0,
\end{array}
$$

Here, $\mu$ is the shear modulus, $b_{n}$ are the coefficients of expansion of the function $F(r)=\sigma_{z z}^{T} / 2 \mu$ in terms of $J_{0}\left(\lambda_{n} \frac{r}{r_{c}}\right), \delta$ is the constant normal displacement along the crack which is determined from the balance condition of the cylinder in the plane of the crack.

$$
r_{c} \int_{0}^{r_{d}} g(t) d t=-\frac{P}{4 \pi \mu}-\int_{r_{d}}^{r_{c}} F(x) x d x
$$

$\mathrm{P}$ is a preset force, applied to the cross-section of the cylinder at infinity.

The final solution of this problem reduces to finding the solution of a Fredholm equation of the second kind relative to the unknown function $\mathrm{g}(\mathrm{t})$ independent on $\delta$ (in particular $\delta$ can be equal to zero).

$$
\begin{aligned}
& \mathrm{g}(\tau)=\frac{2}{\pi} \frac{1}{\alpha} \int_{\alpha}^{1} \mathrm{yF}\left(\mathrm{yr}_{\mathrm{c}}\right) \arcsin \frac{\mathrm{a}}{\mathrm{y}} \mathrm{dy}-\frac{1}{\alpha}\left(\frac{\mathrm{P}}{4 \pi \mu \mathrm{r}_{\mathrm{c}}^{2}}+\int_{\alpha}^{1} \mathrm{yF}\left(\mathrm{yr}_{\mathrm{c}}\right)\right)- \\
& -\frac{2}{\pi} \int_{\alpha}^{1} \frac{\mathrm{yF}\left(\mathrm{yr}_{\mathrm{c}}\right) \mathrm{dy}}{\sqrt{\mathrm{y}^{2}-\tau^{2}}}+\frac{4}{\pi^{2}} \int_{0}^{\infty} \frac{\mathrm{K}_{1}(\xi)}{\xi \mathrm{I}_{1}(\xi)}\left[\frac{\operatorname{sh} \xi \alpha}{\alpha}-\xi \operatorname{ch} \xi \tau\right] \mathrm{d} \xi \int_{\alpha}^{1} \mathrm{yF}\left(\mathrm{yr}_{\mathrm{c}}\right) \mathrm{I}_{0}(\xi \mathrm{y}) \mathrm{dy}+ \\
& +\frac{4}{\pi^{2}} \int_{0}^{\alpha} \mathrm{g}(v) \mathrm{d} v \int_{0}^{\infty} \frac{\mathrm{K}_{1}(\xi)}{\xi \mathrm{I}_{1}(\xi)} \operatorname{ch} \xi v\left[\frac{\operatorname{sh} \xi \alpha}{\alpha}-\xi \operatorname{ch} \xi \tau\right] \mathrm{d} \xi, \\
& 0<\tau<\alpha, \alpha=r_{d} / r_{c} .
\end{aligned}
$$


Integral equation (16) with respect to $g(\tau)$ was solved by a successive approximation technique where function $\mathrm{F}(\mathrm{r})$ was approximated by polynomial with even degrees from 0 to 8.In this case the maximum approximation error which occurs at small Fo is no more than $2 \%$.Stress intensity factor SIF $K_{I}$ is determined according to [3]

$$
\mathrm{K}_{\mathrm{I}}=2 \mu \sqrt{\frac{\pi}{\mathrm{r}_{\mathrm{d}}}} \mathbf{r}_{\mathrm{c}} \mathrm{g}\left(\mathrm{r}_{\mathrm{d}}\right)
$$

In Figure 3 the dependence of stress intensity factor SIF

$$
\mathrm{K}_{\mathrm{I}}^{*}=\frac{2 \mathrm{~K}_{\mathrm{I}}(1-\mathrm{v})}{\mathrm{r}_{\mathrm{c}}^{1 / 2} \alpha_{\mathrm{T}} \mathrm{E}\left(\mathrm{T}_{0}-\theta\right) \sqrt{\pi}}
$$

on time for Fo for different ring-shaped crack sizes $\alpha=r_{d} / r_{c}$ in the case of "rigid" slip joint where $d=0$ is shown. In Figure 4 - the same for $d=2,5 \cdot 10^{-4} \mathrm{~m}$. In case of "flexible" joint SIF is $12 \%$ larger for the same sizes of the cylinder and the shell.

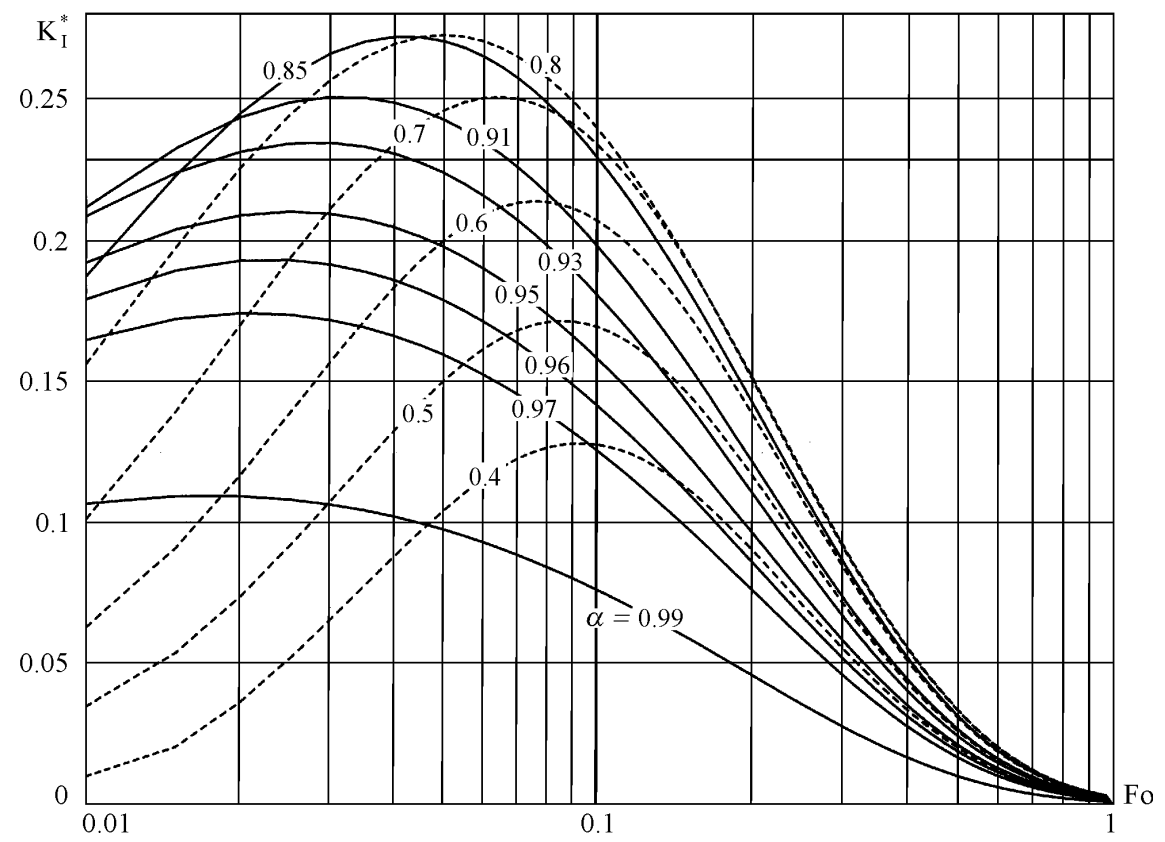

Figure 3: Dependence SIF on time Fo fir different crack sizes (without covering). 


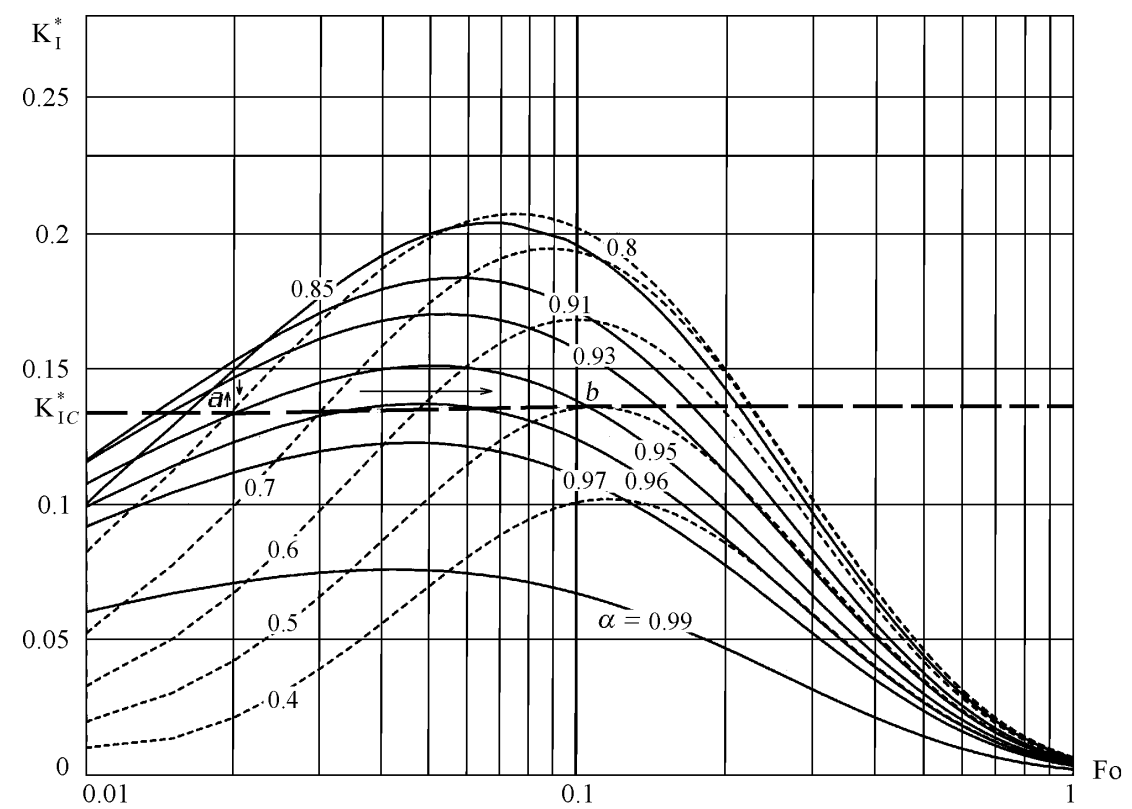

Figure 4: Dependence SIF on time Fo fir different crack sizes (with covering).

\section{Analyses and conclusions}

Let us analyze ring-shaped crack propagation in a covered cylinder starting from relation shown in Figure 4.

Let us assume critical SIF $K_{I C}^{*}=0.136$ (horizontal dotted line). Then, for example, a very small ring-shaped crack of the size $\alpha=0.95$ (the depth is 0.2 $\mathrm{mm}$ ) at the moment of time $\mathrm{Fo} \approx 0.02$ begins to grow unstable, jump-like (point a) and passes the sizes from $\alpha=0.95$ to $\alpha=0.8$ (vertical arrows). After that the crack propagates stable (horizontal arrow) as $K_{I}^{*}$ reaches it's critical value $K_{I C}^{*}$ $=0.136$. Finally the crack stops at the moment of time Fo $=0.12$ (point $b$ ) as the crack size is $\alpha=0,5$ (the depth is $2,5 \mathrm{~mm}$ ).

This fact should be taken into account when covering the cylindrical details by powder materials.

\section{References}

[1] Zhornik A.I. Nonsteady problem of the theory of elasticity for a solid infinite cylinder with a penny-shaped crack, enclosed in a thin shell, International Applied Mechanics, USA - 1993, July - P. 47 - 52.

[2] Zhornik A.I., Zhornik V.A., Kashitsyn L.P. Nonsteady problem of thermoelectricity for a solid infinite cylinder will a ring-shaped crack, enclosed in a thin shell, Advanced Computational Methods in Heat Transfer 
528 High Performance Structures and Materials III

$I V$ : Book of Proceedings. Fourth International Conference on Advanced Computational Methods in Heat Transfer "Heat Transfer 96" Southampton, UK, Boston, USA, 1996.- P. 505 - 516.

[3] Das B.R. Thermal stress in a long cylinder containing a penny-shaped crack on the distribution of stress in a long circular cylinder, Int.J. Engng.Sci.1963,v.1 - P.391-406 